Supporting Information

\title{
Full-Spectrum Cannabis Extract Microdepots Support Controlled Release of Multiple Phytocannabinoids for Extended Therapeutic Effect
}

Almog Uziel ${ }^{a}$, Anat Gelfand ${ }^{b}$, Keren Amsalem ${ }^{b}$, Paula Berman ${ }^{b}$, Gil M. Lewitus ${ }^{b}$, David Meiri ${ }^{b *}$, Dan Y. Lewitus ${ }^{a}$ *

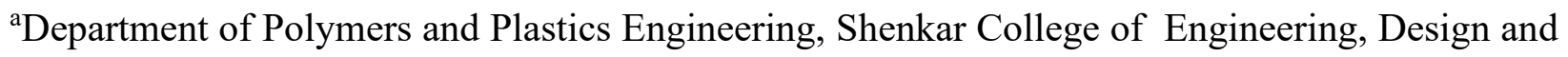
Art, Ramat-Gan 52526, Israel

${ }^{\mathrm{b}}$ The Laboratory of Cancer Biology and Cannabinoid Research, Department of Biology, TechnionIsrael Institute of Technology, Haifa 320003, Israel

*Corresponding authors: dmeiri@technion.ac.il (D.M.); lewitus@shenkar.ac.il (D.Y.L.)

\section{SI METHODS}

Phytocannabinoid Analysis Method 1. Phytocannabinoid identification and quantification was performed using a Thermo Scientific ultra-high performance liquid chromatography (UHPLC) system coupled with a Q Exactive ${ }^{\mathrm{TM}}$ Focus Hybrid Quadrupole-Orbitrap MS (Thermo Scientific, Bremen, Germany). The chromatographic separation was carried out on a Halo C18 Fused Core column $(2.7 \mu \mathrm{m}, 150 \mathrm{~mm} \times 2.1 \mathrm{~mm}$ i.d. $)$ with a guard column $(2.7 \mu \mathrm{m}, 5 \mathrm{~mm} \times 2.1 \mathrm{~mm}$ i.d. $)$ (Advanced Materials Technology, Delaware, USA) through gradient elution at $30^{\circ} \mathrm{C}$. The mobile phase consisted of $0.1 \%$ acetic acid in Milli Q water (solvent A), $0.1 \%$ acetic acid in acetonitrile (solvent B), and methanol (solvent C), all solvents were of LC/MS grade. The multistep gradient 
program starts at $50 \% \mathrm{~B}$ raised to $67 \% \mathrm{~B}$ until $3 \mathrm{~min}$, held at $67 \% \mathrm{~B}$ for $5 \mathrm{~min}$, and then raised to 90\% B until $12 \mathrm{~min}$, held at 90\% B until $15 \mathrm{~min}$, and decreased to $50 \% \mathrm{~B}$ over the next min. The column was held at $50 \% \mathrm{~B}$ until $20 \mathrm{~min}$ for re-equilibration of the system prior to the next injection. Solvent C was initially $5 \%$ and then lowered to $3 \%$ until $3 \mathrm{~min}$, held at $3 \%$ for $5 \mathrm{~min}$, raised to $5 \%$ until $12 \mathrm{~min}$ and then kept constant at $5 \%$ throughout the run. A flow rate of $0.25 \mathrm{ml} / \mathrm{min}$ was maintained and the injection volume was $1 \mu \mathrm{l}$. MS analysis was performed with a heated electro spray ionization (HESI-II) ion source operated in negative mode. Source parameters were as follows: sheath gas flow rate, auxiliary gas flow rate and sweep gas flow rate: 50, 20 and 0 arbitrary units respectively; capillary temperature: $350{ }^{\circ} \mathrm{C}$; heater temperature: $50{ }^{\circ} \mathrm{C}$; spray voltage: 3.00 $\mathrm{kV}$. The scan range was $150-550 \mathrm{~m} / \mathrm{z}$ for all acquisition events. MS was operated in full $\mathrm{MS}^{1}$ mode at 70,000 resolution, and the AGC target was set to $10^{6}$ with a maximum IT of $100 \mathrm{~ms}$.

Phytocannabinoid Analysis Method 2. Phytocannabinoid identification and quantification was performed using a Thermo Scientific UHPLC system coupled with an ISQ ${ }^{\mathrm{TM}}$ EC Single Quadrupole MS (Thermo Scientific, Bremen, Germany). The chromatographic separation was achieved using a Kinetex C18 core-shell column $(2.6 \mu \mathrm{m}, 150 \mathrm{~mm} \times 2.1 \mathrm{~mm}$ i.d. $)$ with a SecurityGuard Ultra column $(2 \mathrm{~mm} \times 2.1 \mathrm{~mm}$ i.d. $)$ (Phenomenex, Torrance, CA, USA), based on the previously described method, with some adjustments. The gradient profile starts at $50 \% \mathrm{~B}$ for $4 \mathrm{~min}$ at a flow rate of $0.8 \mathrm{ml} / \mathrm{min}$, then raised to $67 \% \mathrm{~B}$ at $0.3 \mathrm{ml} / \mathrm{min}$ over $2 \mathrm{~min}$, held at $67 \% \mathrm{~B}$ for $4 \mathrm{~min}$ at $0.3 \mathrm{ml} / \mathrm{min}$, then raised to $90 \%$ at $0.3 \mathrm{ml} / \mathrm{min}$ until $14 \mathrm{~min}$, and held at $90 \% \mathrm{~B}$ for 4 min at $0.3 \mathrm{ml} / \mathrm{min}$. At $18 \mathrm{~min}$, the column was returned to $50 \% \mathrm{~B}$ at $0.8 \mathrm{ml} / \mathrm{min}$ until $24 \mathrm{~min}$ for re-equilibration of the system. Solvent $\mathrm{C}$ was kept constant at $5 \%$ throughout the run. The column temperature was $30{ }^{\circ} \mathrm{C}$ and the injection volume was $5 \mu \mathrm{l}$.The following HESI-II ion source parameters were applied: 50, 7.5 and 0.5 arbitrary units sheath gas flow rate, auxiliary gas flow 
rate and sweep gas flow rate respectively; $395{ }^{\circ} \mathrm{C}$ capillary temperature; $300{ }^{\circ} \mathrm{C}$ heater temperature; $3.00 \mathrm{kV}$ spray voltage. Phytocannabinoids quantification was carried out by selected ion monitoring (SIM) in negative mode. Calibration curves were established in ethanol for standard mixes of $\Delta^{9}$-THCA, $\Delta^{9}-\mathrm{THC}, \mathrm{CBDA}, \mathrm{CBD}, \mathrm{CBG}, \mathrm{CBGA}, \mathrm{CBC}, \mathrm{CBN}$ and CBDV over the range of $100 \mu \mathrm{g} / \mathrm{ml}$ to $0.1 \mu \mathrm{g} / \mathrm{ml}$, and for the obtained Cannabis extract over the range of 200 to $\mu \mathrm{g} / \mathrm{ml} 10 \mu \mathrm{g} / \mathrm{ml}$. 


\section{SI FIGURES}

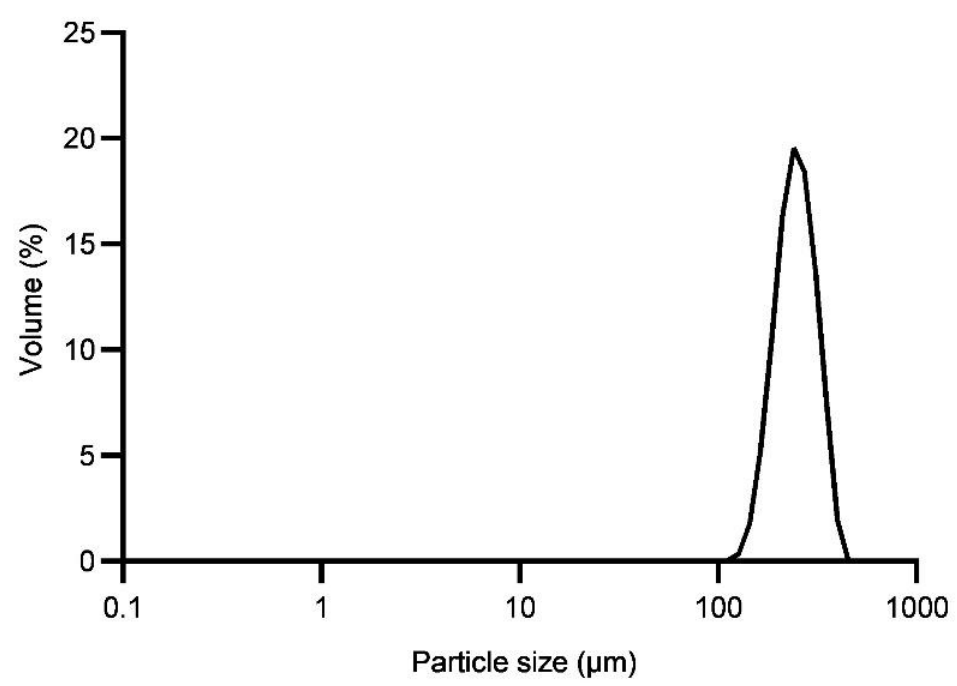

Figure S1. Particle size analysis of Cannabis extract microspheres.

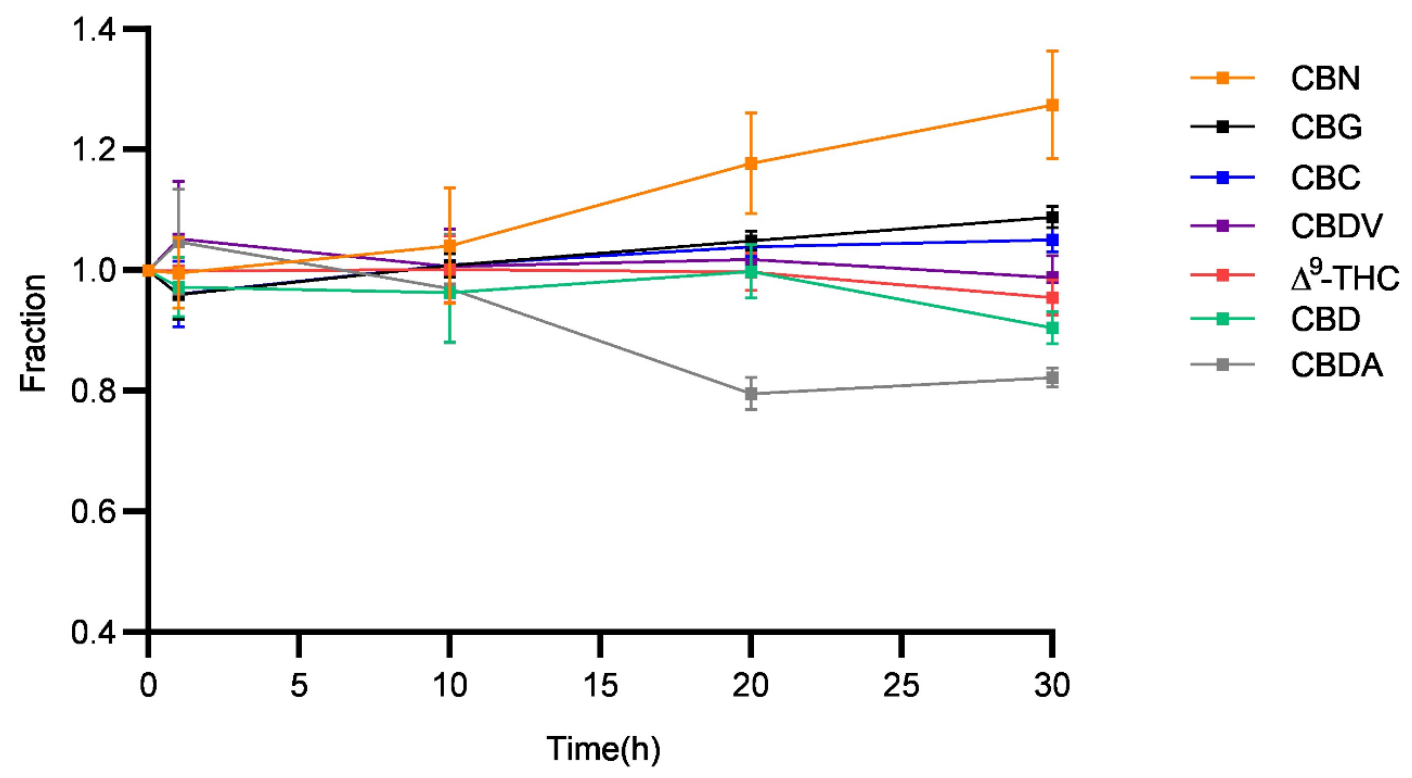

Figure S2. Effect of printing temperature on phytocannabinoids content in the polymer matrix. Change in phytocannabinoid amounts versus time $(n=3$, mean \pm SD). Changes in $C B N$ content 
were analyzed despite its low content in the extract, since it is a known degradation product of $\Delta^{9}$ THC.

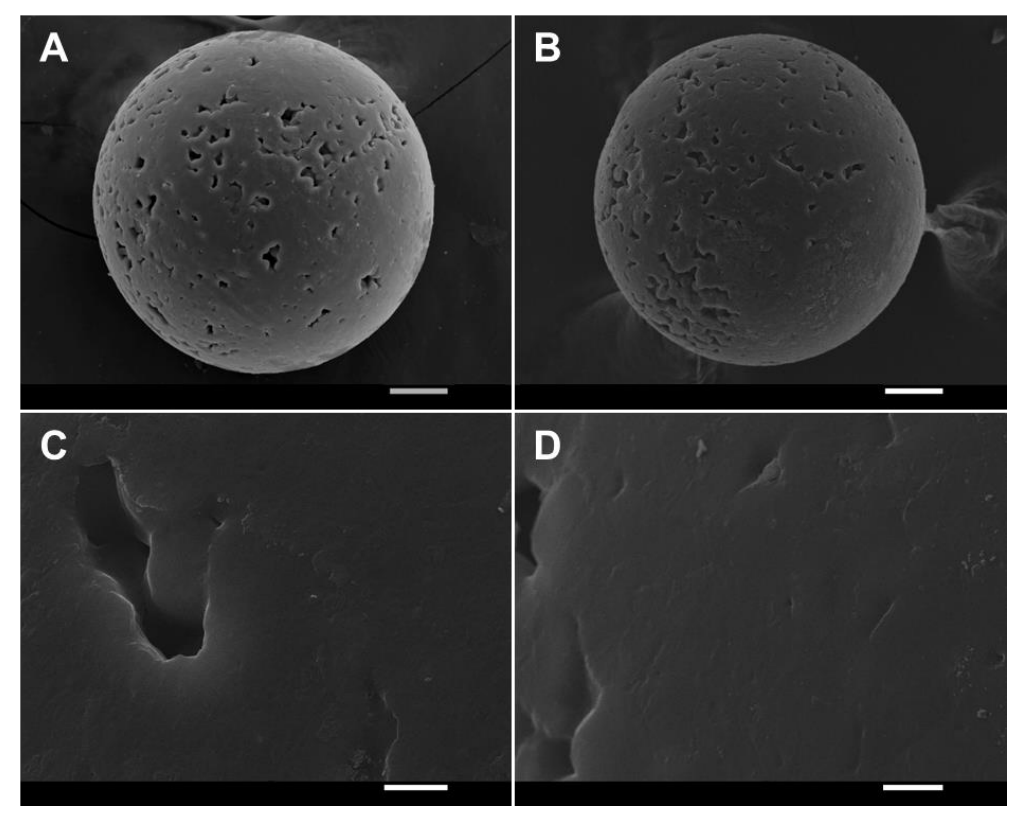

Figure S3. SEM micrographs of blank PCL microspheres (A) before and (B) after 21 days incubation in PBS (pH 7.4) containing 0.1\% w/v Tween 20 at $37{ }^{\circ} \mathrm{C}$. Scale bar: $50 \mu \mathrm{m}$. (C-D) Their corresponding magnified micrographs. Scale bar: $5 \mu \mathrm{m}$.

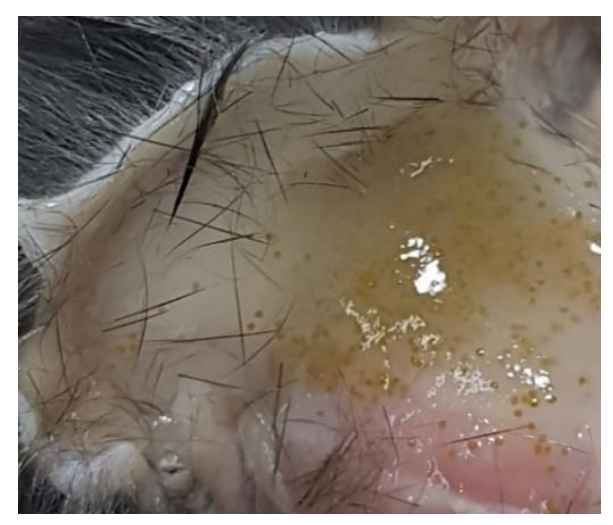

Figure S4. Cannabis extract microspheres removal from mice. The microspheres were collected at different stages of the in vivo release study (image representing microspheres after a 7-day period). 
SI VIDEO

Video S1. Formation of a Cannabis-loaded microdepot upon interaction of the molten jet with the nonwetting surface. 